\title{
Research on Local Problem-focused Charity Sport Event: Multi-stakeholder Perspective and Social Impact Logic Model
}

\author{
Ebe Daigo $^{1}$ and Seiichi Sakuno ${ }^{2}$ \\ ${ }^{1}$ Faculty of Health and Sport Sciences, University of Tsukuba \\ daigo.ebe.ga@u.tsukuba.ac.jp \\ ${ }^{2}$ Faculty of Sport Sciences, Waseda University
}

[Received September 2, 2020; Accepted February 15, 2021; Published online February 26, 2021]

\begin{abstract}
This study on charity sport events in Japan aimed to determine how the participants, event organizer, and beneficial organizations co-create values and make their event effective. Using the Sport Value Framework (Woratschek et al., 2014) as the theoretical framework, questionnaire and interview surveys were conducted on "Value Received" and "Value Created" from the perspective of the three abovementioned stakeholders. The results identified four concepts: "Running event opportunity (marathon participation and commemorative gift)," "Opportunity for interaction," "Motivation for contributing to society," and "Psychological benefits" for the values received by the participants, and five concepts of "Financial support," "Impression of marathon runners," "Social system supporting fundraising," "Communication opportunities," and "Connection with other organizations in the community" for the values created by the participants. These results were presented in a schematic form as a logic model, and allowed for identifying the social impact of charity runs. The present findings will help visualize and communicate the values of these events for communities hosting a charity sport event in the future, event organizers, charity runners, charitable organizations, and donors.
\end{abstract}

Keywords: charity sport events, value co-creation, charity runner, logic model

\section{Introduction}

Japanese people are not considered proactive about fundraising or charities (Charity Aid Foundation, 2018). However, it was reported that the J1 League promptly reacted to the 2011 Tohoku earthquake and tsunami, raising over 180,000 US dollars in the disaster relief charity event (Bell, 2011). Further, sports associations throughout Japan immediately launched reconstruction and recovery projects (Saito and Nakamura, 2012). Recently, the number of Tokyo 2020-related charity projects has increased, and the 2019 Tokyo Marathon successfully fundraised over 500 million yen. Considering these examples, sports events can serve as an important method to address social issues. In particular, by emphasizing the contribution to the host city, charitable activities linked to local social issues have become more popular in Japanese society.

For example, the Osaka Marathon created the
"Osaka category" as a new charitable category to increase positive impacts for Osaka. This trend is quite unique compared to the global trend. Filo (2019), who has studied American and Australian charitable sports events, points out that global charity sports events show the trends of an increased interest in global issues and a concentration of funds. Furthermore, the study by Warner and Dixon (2011) examined that competitiveness is important factor to create a sense of community, while Daigo and Filo (2020) found 'a lack of completion' is more suggested by Japanese charitable sporting events' managers for a sense of community. From these differences revealed by researchers, it seems there are unique aspects in the relationship between charity and sports events in Japan, different from that in other countries.

Based on the literature, this study focused on charity sports events that aim to increase awareness of and solve local issues (hereinafter called "local problemfocused charity sports events"), and aimed to reveal 
how the participants, event organizer, and beneficiary organizations effectively co-create values. The findings will help visualize the values recognized by stakeholders, and serve as a communication tool. Use of the social impact measurement, which are more widely adopted for evaluating sports events, may assist communities hosting a local problem-focused charity sporting event communicate their value.

\section{Literature review}

\subsection{Charity sports events}

Previous research on charity sport events primarily focused on participants' perspectives to reveal contributors to meaningful experiences (Filo et al., 2008), and examining the motivation for participation (Bennett et al., 2007; Won et al., 2010; Hyde et al., 2016). These studies found that participants were attracted to these events through combinations of factors (Hyde et al., 2016), such as physical activity (Snelgrove and Wood, 2010), charitable aspects (Goodwin et al., 2017), and social aspects (Bennett et al., 2007). In other words, these factors interacted with personal values and provided emotional, symbolic, and functional meaning through event participation (Filo et al., 2008).

Furthermore, Inoue et al. (2018) identified that participation may develop empathy among participants, and Hyde et al. (2016) showed that socially supported individuals tended to continue supporting the charitable causes after the event. Although Filo et al. (2018) highlighted that event organizers and participants can co-create values for a charity sport event, their research was event participants-focused.

\subsection{Social impact measurement in sport}

Lee et al. (2013) examined the ways in which sport contributes to society. Growing attention has been paid to the perceived social impact of sport events (Crompton, 2004; Chalip, 2006; Kim and Walker, 2012). Clear evidence of the social effects/impact of general sporting events has not been established (Ohmann et al., 2006), but specifically, perceived social impact entails the perception of intangible benefits to residents of the host community, such as increases in local pride and a sense of community (Crompton, 2004). Several studies have empirically investigated the perceptual social impact associated with sports events, and have suggested that the relationship between the social impact associated with sports events is a multidimensional one that includes both positive and negative elements (Ohmann et al., 2006; Balduck et al., 2011).

However, because they involve major infrastructure projects, only communities with rich resources are able to host large-scale sport events (Taks, 2013). The problems associated with hosting these have created a growing call to focus on small-scale sport events, which can substantially benefit residents (Gibson et al., 2012). The study of Inoue et al. (2018) on social impact assessment in charity sports events extended the understanding of the framework of social impacts proposed by Lee et al. (2013) to the context of smallscale sport events by measuring the social impacts of a participatory sport event. Inoue and Havard (2014) indicated that most previous researchers have conceptualized social impacts in the context of large-scale events, and Oshimi (2020) mentioned that it is possible to develop social impact research targeting smaller and participatory sports events centered on citizen marathons.

Additionally, there are some suggestions on how to measure and visualize social impact (So and Staskevicius, 2015; Mishra et al., 2018). Such proposals can be seen as a growing interest and need for management tools that can measure the effectiveness of activities and lead to socially positive investment in companies, investors and policy writers. Davis et al. (2019) had drawn an impact map and it provided policymakers with evidence-based research upon which to better articulate the case for investment in sport. Lombardo et al. (2019) visualizes how much impact each stakeholder has had and investigated the impact of football clubs on stakeholders and communities in terms of creating social value. Mishra et al. (2018) explained the logic model is a one of useful tool to visualize social impact, emphasizes the positive aspect of the model as a theory of change and stated that many theorists and practitioners have refined and added to this concept.

\subsection{Logic model}

To visualize the social impact, previous research (e.g. Zappalà and Lyons, 2009) has used a logic model. Julian (1997) stated that the logic model originating in the United States Agency for International Development's evaluation practices since the 1960s is a 
simple mechanism for assessing the array of programming aimed at achieving system impacts and/or community goals. As an examples of how the logic model can be used, the W. K. Kellogg Foundation's guide (2004) describes (1) a theoretical model that is used for obtaining funds, explaining to the person who contributes funds, and obtaining agreement, (2) a report with objectives to show the outcome model or uses for evaluation, and (3) an activity model used for management.

The current research takes the third position, and the logic model used in the conclusion section describes the logical linkages among stakeholders, activities, outputs that customers recognized, short-term outcomes, and longer term outcomes.

The reason why this logic model attracted attention in Japan is that "Evaluation: A Systematic Approach" (Rossi et al., 2004) was translated into Japanese (Oshima et al., 2005). In March 2016, the Japanese Cabinet Office announced the policy "Toward the promotion of social impact assessment," wherein the logic model was presented as a method to clarify the rationale for outcomes beyond that. At the same time, the Social Impact Measurement Initiative (SIMI) defined the logic model as a systematic diagram of the available resources for a program and planning activities, referring to the guide by the Kellogg Foundation mentioned above. In SIMI, "sports" was selected as a research theme for their third term, and a logic model was created for various sports events, aiming for generalization (SIMI, 2019). However, these activities are still in the primary stage. There is still an opportunity to discuss the method of visualizing the social impact of sports events using a logic model by accumulating cases.

\section{Methods}

\subsection{Research framework}

This study used the Sport Value Framework (SVF; Woratschek et al., 2014) as its theoretical framework. The SVF is incorporated in Service-Dominant Logic (SDL; Vargo and Lusch, 2004), and its value has been co-created through the integration of resources and collaboration among various stakeholders. The framework was developed to examine value co-creation in sports management; it highlights that consumers (i.e., event participants) and event organizers (i.e., event manager and sponsors) are involved in an interrelated process to create values through their events.

This study integrated this framework into the contexts of charity sports events. Filo et al. (2018) used SVF to position sports event participants as social value co-creators for the manager. However, Woratschek et al., (2014) understood that past studies determined that the basic relationship between actors (microlevel), and SVF was not limited to these two actors, this finding is significant as SVF demands broader analyses that consider the entire network of actors involved in value co-creation (meso-level).

The SVF advances ten foundational premises (FPs) that take into account the unique characteristics of sports management. These basic assumptions cover the SDL and each can be understood in relation to the charity sports event context. FP 7 value is always co-created by firms, customers and other stakeholders, and the research including several surveys across various stakeholders, will help improve understanding. As mentioned in the literature review, research on charity sports events is based primarily on participants (Daigo and Filo, 2020), hence there is an opportunity to investigate more diverse stakeholder perspectives.

In FP 9, co-created value depends on the context. Therefore, by clarifying three specific stakeholders in this study and describing the event type, the framework promoted by Woratschek et al. (2014) can be applied to charity sports events that fundraise for local issues in Japan. Also, most previous research on charity sports events addresses Western culture and the current study examines charity sports events in an Asian context.

As explained earlier, previous studies on charity sports events relied heavily on data collected from event participants (Filo et al., 2008; Won et al., 2010). The present study reflects research data collected not only from participants but also from beneficial organizations and event organizers (marathon committee) (Daigo and Filo, 2020) in an Asian context. This study focused on the participants, beneficial organizations, and event organizers as the stakeholders and prepared the following research questions:

RQ1: What kind of values are created/received by charity runners?

RQ2: What kind of values are created/received by beneficial organizations?

RQ3: What kind of values are created/received by the marathon committee? 


\subsection{Research context}

Daigo and Filo (2020) explained three reasons for why charity sport events have become increasingly popular in Japan. First, Japan has suffered a number of natural disasters in recent years, and sport has been integral in aiding in recovery (Lankston, 2011). Second, sport events are viewed as increasingly important in Japan as a catalyst of Japan's rebirth (Cha, 2016). Third, changes in the Japanese tax code effective from 2012 have incentivized donations to non-profit organizations via charity sport events (Harada, 2015). More specifically, the current investigation was conducted at the Sendai International Half Marathon to examine its efforts for co-creation of values. The marathon was selected as a research site because its unique status as a local-focused charity sport event can provide novel insight into the literature on the social impact of sport events.

\subsection{Procedures}

\subsubsection{Survey for charity runners}

The respondents were 98 people who provided their contact information out of 100 who registered as charity runners for the 2019 race. The web survey was conducted for a month starting three days after the marathon event from May to June 2019.

The survey items for basic characteristics included gender, age, address, how many times they participated in the Sendai International Half Marathon, and their charity runner experience. Participants were also asked how they covered their charity entry fee and about whether they feel burdened by these expenses, planned to claim a tax deduction for charitable contributions, were satisfied with the charity commemorative gift, and whether they would participate again. Lastly, they answered two open-ended questions based on the SVF (Woratschek et al., 2014; Filo et al., 2018): "As a charity runner, what kind of values did you contribute to for the Sendai International Half Marathon?" and "What kind of values do you think you received by participating as a charity runner in the Sendai International Half Marathon?"

\subsubsection{Survey for charitable organizations}

The respondents were Organization A (orphanage) and Organization B (para-sports) from among the beneficial organizations of the marathon. The interviews were conducted in November 2019 for $60-70$ minutes and were recorded. Face-to-face semi-structured interviews were used.

The survey items included gender, age, and service years. They were also asked how they would use the funds raised at the event, its positioning in their program, how to evaluate the outcome, other opportunities for fundraising, and the current status and challenges in communication with charity runners. Additionally, they answered two questions based on the SVF (Woratschek et al., 2014; Filo et al., 2018): "What kind of values, other than money (financial support), did your organization receive from the charitable activity of Sendai International Half Marathon?" and "What kind of values does your organization create?"

\subsubsection{Survey for marathon committee}

The first interview was conducted in May 2019 using a face-to-face semi-structured interviewing method. A key person of the marathon committee (Mr. W) was invited to reveal the current status and challenges of the marathon. The interview guide comprised two sections. First, demographic questions collected the interviewee's age, sex, education level, and the length of time they had spent working for the event. The second involved the cash-flow process of the funds raised, the catalyst for starting the marathon event fundraiser, how great the earthquake damages were in the local area, when the charity began, and how communication with charity runners and beneficiary organizations was facilitated.

The second interview, with Mr. W and three staff members (Mr. X, Mr. Y, and Mr. Z) of the Culture and Tourism Bureau, Sendai City, which plans and manages the marathon, was conducted as a group discussion in September 2019. This interview lasted about 90 minutes and was digitally recorded by the author. At first, demographic data was collected including the interviewee's age, gender, education level, and the amount of time they had spent working for the event and organization. After that, based on the results of a web survey to understand the current status of participants, their opinions were requested. They were also provided a logic model based on the participant survey results and discussed values created/received by other stakeholders and charity runners. Lastly, their opinions on values created/received from the marathon committee and government's point of view were gathered by using the same questions as were asked of the beneficial organization: "What kind 
of values, other than money (financial support), did the marathon committee gain from the charitable activity of Sendai International Half Marathon charity event?" and "What kind of values did the marathon committee create?".

\subsection{Data analysis}

Descriptive statistics were conducted for questions with options in the participant survey data. However, statistical analysis was not conducted because of low response rate. The free description questions for the participants and the interview data from the beneficial organizations and the marathon committee were analyzed using thematic analysis (Braun et al., 2016) in the narrative paradigm. Thematic analysis is a method for systematically identifying, organizing, and offering insight into patterns of meaning and themes across a data set (Guest et al., 2011). It also provides the opportunity to code and categorize data into themes (Ibrahim, 2012), for example, how issues influence participant perceptions, and data can be displayed and classified according to their similarities and differences (Miles and Huberman, 1994). Data collected based on observations that rely on participants' feelings or attitudes, data investigation, and generating theory are combined with its analytical element (Braun and Clarke, 2006; Crawford et al., 2008). It is beneficial to allocate a narrative to the diverse data to gain a clear, logical understanding of the participants' thoughts and to convey their experience (Crawford et al., 2008).

The data analysis processes derived from the Miles and Huberman (1994) model include data reduction, display, and rendering. After collecting the data, researchers should tabulate it using document filing prior to preparing and organizing the content of the data. In the current research, the low date was sent to a third party transcript company and exported to a Microsoft Word file. Then, the author followed Bogdan and Biklen's (2007) argument that in Thematic Analysis, data must be read at least twice (Ryan and Bernard, 2003). The second phase involved highlighting the sentences from each participant that could be used, for example, to answer the study's questions from the excerpts from the participant's full text. The third phase used highlighted sentences and then broke the data into smaller segments or themes.

The second main step of the Miles and Huberman Model (1994) is data display, through which data are retrieved and ordered. This allows the researcher to explore any differences, similarities, and interrelationships by entering the data into conceptual clusters for analysis. Data display was used descriptively to gain conceptual coherence by collating items related to each research question (Miles and Huberman, 1994). In addition, direct quotations provide supportive evidence for data interpretation (Patton, 2002).

The third step comprises data drawing and conclusions. Firstly, this involves the notation of any themes and the relevance of any statement, especially if presenting similarity or contrast. Then, categories of information that can go together are established and grouped, and interrelations among factors or themes are identified.

The current research tried to draw a logic model in discussion. When creating a logic model, stakeholders listed from participants' open-ended question and interviews' result. Next, the output was described based on the value revealed from the charity runners. Then, the author compared the outcomes of the SIMI's original model (2019) and deleted the ones that were not mentioned in the survey. Values identified in the current study revised the wording and edited their expressions to fit the context. In the original logic model (SIMI, 2019), each value was placed on the shortterm, the medium-term, and the long-term outcomes and according to the Logic Model Development Guide (W.K. Kellogg Foundation, 2004), the short-term output is 1 to 3 years and long-term output is 4 to 6 years. Baker Tilly (2012) defined that primary outcomes as the outcomes that directly and immediately result from the intervention in question and secondary outcomes as the long term results that flow from primary outcomes. In the context of the current study, the authors discussed the short-term outcomes are events happen within one year, the medium-term outcomes are 1 to 3 years, and the long-term outcomes are 4 to 6 years. However, there are no enough interview data to decide the order between medium and long-term outcome. Through the discussion above, authors combined them into the long-term outcome.

\subsection{Ethical clearance}

The research goals and purpose of the study were explained in the email requesting runners to participate, and only those who agreed sent their responses. All interviewees remained anonymous. 


\section{Results}

\subsection{Research on the current status of charity run- ners}

The response rate was low (19\%). Therefore, statistical analysis was not conducted, and only descriptive statistics were obtained. Table 1 provides the main results of the survey. Regarding how respondents covered their charity event entry fee, over $90 \%$ of respondents indicated that they paid with their own money. Additionally, there was no significant difference in respondents' feeling of being burdened by the entry fee depending on their place of residence or age.

Regarding their next participation, 31\% of respondents chose "I want to participate in the event again as a charity runner," $36 \%$ chose "I want to participate in the event again in the open division," and the rest chose "Not yet decided."

Table 1 Charity runners' index.

\begin{tabular}{lrc}
\hline Gender & $\mathrm{n}$ & $\%$ \\
\hline Male & 16 & $84 \%$ \\
Female & 3 & $15 \%$ \\
\hline Age & & \\
\hline $30-39$ & 1 & $5 \%$ \\
$40-40$ & 6 & $11 \%$ \\
$50-59$ & 10 & $74 \%$ \\
Over 60 & 2 & $10 \%$ \\
\hline
\end{tabular}

Charity run for Sendai International Half Marathon

\begin{tabular}{lrr} 
First time & 14 & $74 \%$ \\
Second or third times & 5 & $26 \%$ \\
\hline General participation for Sendai International Half Marathon \\
\hline No experience & 4 & $21 \%$ \\
One or two times & 8 & $42 \%$ \\
Three or four times & 7 & $37 \%$ \\
\hline
\end{tabular}

Charity run prticipation for other running event

$\begin{array}{lrl}\text { I have been participated } & 4 & 22 \% \\ \text { No experience } & 15 & 78 \%\end{array}$

How do you cover your charity entry fee and donation?

Own money $18 \quad 95 \%$

Support from spouse, parent(s) or child(ren) $\quad 1 \quad 5 \%$

\begin{tabular}{lrr} 
Feeling of burden of charity entry fee and donation \\
\hline Very expensive & 1 & $5 \%$ \\
Expensive & 11 & $57 \%$ \\
Fair & 7 & $36 \%$ \\
Reasonable & 0 & $0 \%$ \\
Very reasonable & 0 & $0 \%$ \\
\hline
\end{tabular}

\subsection{Values created by each stakeholder in value co-creation}

First, the answers of charity runners to the open-ended questions were coded and categorization to establish common concepts between "Value Received" and "Value Created." For "Value Received," the question was "What value do you think you receive from your experience as a charity runner (return, benefit or merit)?" and for "Value Created," the question was, "What kind of value do you think you create as a charity runner (support or contribution)?"

All the respondents answered the open-ended question, but seven runners responded, "I don't have an opinion," "I've never thought about it" or "no idea" to the "Value created" question. By combining the answer for two questions, the description of 72 words by a person was confirmed. The result confirmed the four concepts: "Social contribution opportunity ( $\mathrm{n}=11)$," "Running event opportunity (race participation and commemorative gift) $(\mathrm{n}=5)$," "Opportunity for interaction $(\mathrm{n}=2)$," and "Psychological benefits $(\mathrm{n}=2)$ ". These can be considered direct outcomes.

After a group discussion between the participants at the marathon committee's office about the results of the survey, the values of the charity run as recognized by the event organizer were identified, and those according to the beneficial organizations were drawn from the interviews. Five themes in the co-creation of values of the charity run were identified and shared between the two parties.

Additionally, "Runner (General, Charity and Elite)," "Spectator (Family, Friend and member who related to the beneficial organization)," "Supporter (Organizing committee, Volunteer, Sendai City (Council), Local stores, Community that a beneficial organization belongs to, and Media) were identified as stakeholders involved in value co-creation through the open-ended questions to the participants and the interviews with the beneficial organization and the event organizer.

Theme 1: Financial support

It is evident that money donated by charity runners supports the community through the beneficial organization. Group A used donated money to purchase sports equipment, and Group B used it as resources for disabled athletes-specifically, for operating expenses of baseball tournaments and table tennis games, and for assisting athletes in attending interleague games. 
However, as donations are unstable, beneficial organizations must mainly utilize their own financial resources to make their projects visible and maintain their scale. Organization B reported that stability was key to further develop the project, saying, "The amount of donations is unpredictable. Setting up a foundation is possible if this amount of funding is always promised in the future."

Theme 2: Impression of marathon runner

Second, the results showed that the impressions of marathon and sports had a positive impact on the charity run. The respondents said that the event organizer's policy that the beneficial organizations should be selected from "organizations contributing to local communities and their revitalization or organizations contributing to communities in Sendai" was highly valued during the selection, and the beneficial organizations were determined in "considering an affinity with marathon races."

In the answers to the survey with the organizations, Organization B said, "Donations through sporting events always sound positive," and Organization A said

It gives a healthy impression... Marathon fundraising is a very good story that is also easy to understand for small children. The information on donors is not important for our staff members, but we enjoyed cheering the race on the roadside... A marathon race in early summer sounds very positive. The weather is perfect.

These comments highlighted the general healthy impression of sports and the privilege of enjoying the outdoors. He added, "The values received through cheering runners at our familiar local place have a positive influence. I cannot explain it in words, but it is like healthy grownups are engaged in something positive."

Theme 3: Social system supporting charity runners

Third, it was indicated that the environment and system supporting charity runners as donors are important. Organization B said, "We have not yet been incorporated. (The other organization) and public benefit corporations may give something back to donors. It is our challenge." This indicates that social systems built around fundraising may lead to further development. A comment that the organizations look for ways to publicly announce that their activities are supported by donations can be considered as something relating to social systems. Organization B said

If we can receive the same amount every year, we want to change the name of the fund-subsidized project, to go public, and to announce the result of spending. But we cannot show the details to our donors at this moment. The disclosure may motivate our donors.

The event organizer understood that a marathon event provides opportunities to donors and locals who are willing to socially contribute, saying "Those who are highly conscious about social action think this event serves not only sports but also for community activation in Sendai city."

Theme 4: Communication opportunities

Fourth, many respondents highlighted the importance of communication among stakeholders. The interview with the event organizer revealed that the idea to organize the charity run was proposed by the department organizing the committee that Organization A belongs to. However, staff members of the event organizer were not able to meet the runners on the day. Organization B said "Currently, we are not able to support them on the day because we are engaged in the management of the marathon race."

Organization B highlighted a lack of communication, adding "We appreciate runners for choosing us, but we have no way to communicate it to them." Regarding cheering the runners on the roadside, Organization A said, "Runners give a high-five or tell us about their money donation, which creates some connections." They also said, "Children in our orphanage loved high fives and letters. Some runners told these children that they were sponsoring them, and these children showed their interest in cheering again in the next event." Both beneficial organizations were ready to listen to opinions on fund spending from the runners, thus, facilitating effortless communication may bring more benefits.

Theme 5: Connection with other organizations in the community

Lastly, the results identified an opinion about social action solving local issues by activating the community, particularly by establishing or reinforcing a relationship with other local organizations. Specifically, volunteers and voluntary organization were highlighted in all the interviews. The event organizer explained, "This region has more volunteers than average in Japan. People are very proactive," with examples of activities during the 2002 FIFA World Cup. Organization B indicated that further development of this marathon event could make use of the local advantage that voluntary activities in sporting 
events are very popular, adding, "We want to maintain and grow this project after the Paralympic Games. Since volunteers are essential in this activity, we will also make an effort to assist them better."

\section{Discussion}

Using a thematic analysis with the survey results, four themes were revealed: "Social contribution opportunity," "Running event opportunity" (race participation and commemorative gift), "Opportunity for interaction," and "Psychological benefits." "Social contribution opportunity" supported the research results of Inoue et al. (2018) on small-scale charity sports events. However, runners used the words "I just did it because I wanted to," and "Selfsatisfaction" - not only in the negative sense - and it is recognized that the effect of donation is not fully felt by the charity runner. The theme of "Running event opportunity," was supported by the effectiveness of incentives named "prizes and incentives," identified by Filo et al. (2018). However, the incentive of this study was running equipment, which might be useful for their training, but might not have enough appeal as a charity. "Opportunity for interaction" was one of the general motives for participation in sports (Funk et al., 2007) and entertainment events (Lee et al., 2004). The sense of superiority in the theme of "Psychological benefits" might be unique to the charity context. In the interview with the event committee, it was revealed that people in this area would rarely rely on monetary donations. While this reflects a traditional Japanese sense of values, it may become a barrier to adopting fundraising as a tool in a future charity sports event.

In addressing the RQs, themes from interviews with the marathon committee and donation recipient organizations became clear. In "Financial support," it was important that support was gathered in the form of "money," which makes a specific contribution (Garcia-Rodriguez and Romero-Merino, 2020). Financial support in this research, which was one of the economic effects, also affected social impact in a longterm perspective. In the "Impression of marathon runners," positive opinions were heard, and revealed that the story of the marathon fit well with the purpose of supporting children. "Social system supporting charity runner" coincided with respondents' opinion that "Japan still lacks understanding of donations for the society." To overcome this, setting up a donation sys- tem or platform as part of a large-scale city marathon event and a tax deduction announcement were evaluated with a high value. Regarding the themes of "Communication opportunities" and "Connection with other organizations in the community," initiatives like the establishment of the charity run category emerged from a conversation between the council to which Organization A belongs to and the marathon committee. Moreover the event created interaction opportunities between Organization A and charity runners on the event day. The request from the beneficial organization to communicate with their charity runners before, during, and after the event suggested the importance of the pre-post event (Daigo and Filo, 2020). The importance of collaboration between sponsors and participants is shown in the research by Smith et al. (2015), and the current study also investigated collaboration between the marathon committee and the beneficial organization. In the current study, the four themes from the charity runners and five themes from the marathon committee and beneficial organizations reaffirm that value in sport events' value is created through collaboration among multiple stakeholders utilizing a variety of resources (Vargo and Lusch, 2004).

\section{Conclusions}

Referring to the logic model for standard sports events (Social Impact Measurement Initiative, 2019), the stakeholders were modified in this study, the selection of outcomes was determined based on interview results, and a postscript was added. The bold entries are characteristics found in this charity run.

Compared to the logic model for standard sports events (SIMI, 2019), it did not receive feedback for "Improvement of Health/Physical Strength." It showed that value creation through sports is more expected more at events than at the individuals level.

First, the stakeholders were listed as one resource category. There were options to describe various resource types in this input space including financial resource or facilities, but in this study, the author referred to the sports event logic model created by SIMI (2019) and decided to describe the stakeholders referencing the study's results. The output reflected those results. Initially, the short-term outcomes were "2. Sports are for all," "3. Sports fit for daily activity," and "4. Expand the value of sports," "5. Increase participants and recognition for the charity run," and "6. Enhance community" were positioned as long- 
term outcomes.

Short-term outcomes are feelings or actions that happen within days or months after the event state. For example, the experience of running in a pleasant climate is expected to lead to continued sports or participation in sports event in the same season. In "Expanding the value of sports", runners will receive a kind of 'thank you' letter from the beneficial organization within one month after the event participation. Runners who participated as a charity runner for the first time experience appreciation from others for participation.

Next is the long-term outcomes. The city marathon, the subject of this study, is usually an once-a-year event; it is expected that the positive impressions of charity runners will contribute to the familiarity and popularity of charity events. Participation of closer friends and family members, in particular, will motivate potential attendees of the next event and give them the option of a charity runner. In addition, while charity runners gain information about the related issue and increase their interests in it through participating in the charity run, to understand the reality of the issue at the community level, know about the impacts of the donation from reports of the organization, and be motivated to support, including volunteering for the local community, are seen as long-term outcomes.

As for the theoretical implications, this study successfully broadened the literature to include event organizers and beneficial organizations as stakeholders to better comprehend the theory of value co-creation in sports. The SVF is a general theory with a high level of abstraction (Gerke et al., 2020), and there are few studies that link to empirical data. SVF, which indicates, "Co-created value is always value-in-context" (FP9), requires researchers to have a localized perspective to fully understand its background. Moreover, there are few studies examining this in an Asian context.

Second, we captured the broader stakeholders by conducting surveys among three parties. Although it is assumed that there are multiple actors that can provide a 'more holistic' status in SVF, it is difficult to know everyone who could contribute to an event. The study also suggested that sports event management scholars should focus on actors' networks and inclusive empirical research designs rather than on isolated elements and single actors.

Finally, since a couple of common statements about the challenges and difficulties were found among the three parties, value co-creation in a charity sports setting started to produce positive results and gain a common understanding of negative factors. The need to incorporate efforts before and after the event into the framework was emphasized in Woratschek (2014), but to understand negative impacts, more empirical findings are needed to verify and consolidate the SVF.

Regarding the managerial implications, this study will provide indications for linking sports and the beneficiaries-payee relationship from the public value perspective. In other words, they will show that running events are not only for athletes and top runners, and

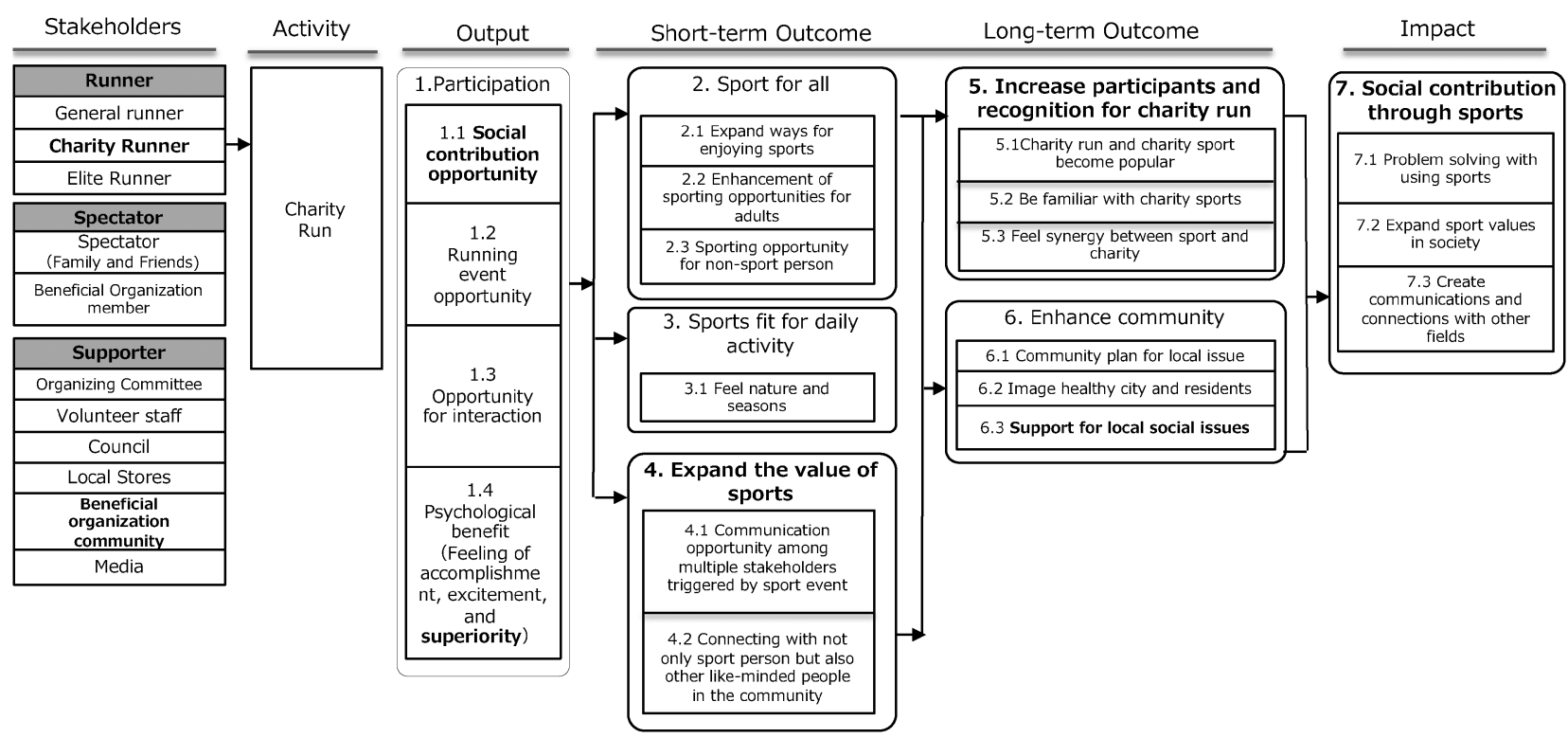

Figure 1 Logic model for charity run 
that sports will be able to help solve social challenges through charity runs. In particular, it is difficult to show achievements and impacts of charity projects with economic indicators. Therefore, this as well as future studies in this field will clarify the values using sports as a catalyst.

\section{Limitations and future research}

In the survey, the response rate of participants was extremely low. This may have been due to charity runners also receiving the questionnaires given to the general participants and not having the time to answer another questionnaire. In future research, large-scale panel data can illuminate the present findings more clearly, including micro, meso, and macro viewpoints to clarify the understanding of FP5 among SVF.

In this study, the common items from the event manager interviews (4 people) and the beneficiary organizations ( 2 people) were derived and used as the event outcome. This work and the creation of a logic model was completed by the first author, whose subjectivity was strongly reflected. In future research, it will be necessary to collect organizational information and archival data (Gerke et al., 2020) and analyze it with more than one person. There is no template for creating a logic model (Carrol and McKenna, 2001) and several different versions exist (Knowlton and Phillips, 2012). In addition, the mid-outcome in SIMI (2019) could not be confirmed in this study. For future research, an interview guide must be designed including a time-frame to identify the position and relationship between values, selecting which factor locates the short-term outcome or which factor is the mid-term outcome. The current study is a starting point for using the logic model as a visual tool in sports management research.

This study also ignored the complex situation between local social problems and charity sports event delivery systems. Expecting such systems to quickly change in response to emerging local issues may prove overly optimistic. Wong-Reiger and David (1995) stated that the logic model shows the chain of "if-then" reasoning. Originally it was desirable for the social impact to state both positive and negative (Liu, 2016), but hopeful connections by inference between outcome and outcome cannot be eliminated. Furthermore, not every outcome is actually measured. The outputs of the activities and the direct outcomes were extracted exploratively, and the other outcomes were only the contents confirmed by a couple of comments in the interview. Keane et al. (2019) provide a comprehensive review and critical analysis of previous and current methods for assessing value creation in sport and note that a plethora of conflicting methods have been used. Among a series of the social impact research in sport, Social Return on Investment framework (SROI), which is a social value survey based on the cost-benefit analysis (CBA), has been in the highlighted since 2010 (Davis et al., 2020) and one of most popular indicator in this field (Lombardo et al., 2019), and is used globally in various policy areas, especially by public institutions and third sector organizations (Fujiwara, 2014; Millar and Hall, 2013). It is built on a theory of change in the form of a logic model, which is developed in consultation with stakeholders and this point is a common with a SVF, the current study relied on. However, SROI expresses the value of social outcomes in relation to the cost of achieving them and uses money as a common metric. For future research when the focuses on more largescale charity event (e.g. Tokyo marathon and Osaka marathon), other methodology including SROI should be considered.

In future research, comparing the context of charity sports events in Japan with data and research of charity sports events held in other countries is possible. This may strongly support Daigo and Filo's (2018) argument indicating differences in charity sports event results between countries where such events are well established, such as Australia, the US and the UK (e.g., Filo et al., 2008; Filo et al., 2020), and Asian countries (Inoue et al., 2018). Second, the potential influence of the post-event warm glow effect postevent could be addressed through data collection at multiple time points. In the current context, longitudinal data collection is required (Filo et al., 2012), and this study allows for addresses this requirement.

\section{Acknowledgments}

The research was supported by the Sasakawa Sports Research Grant from Sasakawa Sports Foundation. We also thank the anonymous reviewers for their useful comments and detailed suggestions.

\section{References}

Balduck, A. L., Maes, M., and Buelens, M. (2011). The social impact of the tour de France: comparisons of residents pre- and post-event perceptions. Eur. Sport Manag. Q., 11(2): 91-113.

Baker, T. (2012). Edinburgh leisure: Social impact evaluation. The City of Edinburgh Council. http:// www.socialvalueuk.org/app/ uploads/2016/04/ EDL-305-SROI-Summary-Report-Main- 
FINAL.pdf (accessed 2020-12-13).

Bell, J. (2011). Japan earthquake relief soccer match. The New York Times, 28.

Bennett, R., Mousley, W., Kitchin, P., and Ali-Choudhury, R. (2007). Motivations for participating in charity-affiliated sporting events. J. Cust. Behav., 6(2): 155-178.

Bogdan, R. and Biklen, S. K. (2007). Qualitative research for education: an introduction to theory and methods. Pearson/Allyn and Bacon.

Braun, V. and Clarke, V. (2006). Using thematic analysis in psychology. Qual. Res. Psychol., 3(2): 77-101.

Braun, V., Clarke, V., and Weate, P. (2016). Using thematic analysis in sport and exercise research. Routledge handbook of qualitative research in sport and exercise. Routledge.

Carroll, JB. and McKenna, J. (2001). Theory to practice: Using the Logic Model to organize and report research results in a collaborative project. J. Fam. Consum. Sci., 93(4): 63-65.

Cha, V. (2016). Role of sport in international relations: National rebirth and renewal. Asian Econ. Policy Rev., 11(1): 139-155.

Chalip, L. (2006). Towards social leverage of sport events. J. Sport Tour., 11(2): 109-127.

Charity Aid Foundation (2018). World Giving Index. https://www. cafonline.org/about-us/publications/2018-publications/caf-worldgiving-index-2018 (accessed 2020-09-07).

Crawford, P., Brown, B., and Majomi, P. (2008). Education as an exit strategy for community mental health nurses: A thematic analysis of narratives. Ment Health Rev (Brighton), 13(3): 8-15.

Crompton, J. L. (2004). Beyond economic impact: An alternative rationale for the public subsidy of major league sports facilities. J. Sport Manag., 18(1): 40-58.

Daigo, E. and Filo, K. (2018). The trends in Japanese charity sports events: A study of role for sports events to solve international and social issues. Sasakawa sports foundation grant report 2017: 101-107. (Japanese)

Daigo, E. and Filo, K. (2020). Using a sport event to create a sense of community: Charity sport event manager perspectives. Event Manag., 24(1): 57-73.

Davies, E. L., Taylor, P., Ramchandani, G., and Christy, E. (2019). Social return on investment (SROI) in sport: a model for measuring the value of participation in England, International Journal of Sport Policy and Politics, 11(4): 585-605.

Filo, K., Funk, C. D., and O'Brien, D. (2008). It's really not about the bike: Exploring attraction and attachment to the events of the Lance Armstrong Foundation. J. Sport Manag., 22(5): 501525.

Filo, K., Groza, M. D., and Fairley, S. (2012). The role of belief in making a difference in enhancing attachment to a charity sport event. J. Nonprofit Public Sect. Mark., 24: 123-140.

Filo, K., Lock, D., Sherry, E., and Quang Huynh, H. (2018). You belonged to something: exploring how fundraising teams add to the social leverage of events. Eur. Sport Manag. Q., 18(2): 216236.

Filo, K. (2019). The Synergy between sport events and charity: Background, research, and ongoing trends. Presentation material at CANPAN $\cdot$ NPO forum, Nippon foundation.

Filo, K., Fechner, D., and Inoue, Y. (2020). Charity sport event participants and fundraising: An examination of constraints and negotiation strategies. Sport Manage. Rev. 23(3): 387-400.

Funk, C. D., Toohey, K., and Bruun, T. (2007). International sport event participation: Prior sport involvement; Destination image; and travel motives. Eur. Sport Manag. Q., 7(3): 227-248.

Garcia-Rodriguez, I. and Romero-Merino, M. E. (2020). Financing nonprofit organizations. Routledge Studies in the Management of Voluntary and Non-Profit Organization. Routledge.

Gerke, A., Woratschek, H., and Dickson, D. (2020). The sport cluster concept as middle-range theory for the sport value framework. Sport Manag. Rev., 23(2): 200-214.

Gibson, H. J., Kaplanidou, K., and Kang, S. J. (2012). Small-scale event sport tourism: A case study in sustainable tourism. Sport Manage. Rev., 15(2): 160-170.

Goodwin, A., Snelgrove, R., Wood, L., and Taks, M. (2017). Leveraging charity sport events to develop a connection to a cause. Event Manag., 21(2): 175-184.

Harada, S. (2015). Policy processes in the 2011 revision of the nonprofit organization law in Japan: Based on the advocacy coalition framework. The Nonprofit Review, 15(1): 1-12. (in Japanese).

Hyde, M. K., Dunn, J., Bax, C., and Chambers, S. K. (2016). Episodic volunteering and retention: An integrated theoretical approach. Nonprofit Volunt Sect. Q., 45(1): 45-63.

Ibrahim, A. M. (2012). Thematic analysis: A critical review of its progress and evaluation. W. East J Soc. Sci., 1(1): 39-47.

Inoue, Y. and Havard, C. T. (2014). Determinants and consequences of the perceived social impact of a sport event, J. Sport Manag., 28(3): 295-310.

Inoue, Y., Heffernan, C., Yamaguchi, T., and Filo, K. (2018). Social and charitable impacts of a charity-affiliated sport event: A mixed methods study. Sport Manage. Rev., 21(2): 202-218.

Julian, D. (1997). The utilization of the logic model as a system level planning and evaluation device. Eval Program Plann., 20(3): 251-257.

Kim, W. and Walker, M. (2012). Measuring the social impacts associated with Super Bowl XLIII: Preliminary development of a psychic income scale. Sport Manage. Rev., 15(1): 91-108.

Knowlton, W. L. and Phillips, C. C. (2012). The Logic Model Guidebook: Better Strategies for Great Results. SAGE Publications, Inc.

Lankston, C. (2011). Japan bid for Olympics to aid tsunami recovery. http://www.telegraph.co.uk/sport/olympics/news/8640217/ Japan-bid-for-Olympics-to-aid-tsunami-recovery.html (accessed 2020-06-24).

Lee, C., Lee, Y., and Wicks, B. E. (2004). Segmentation of festival motivation by nationality and satisfaction. Tour. Manag., 25(1): 61-70.

Lee, S., Cornwell, B., and Babiak, K. (2013). Developing an instrument to measure the social impact of sport: Social capital, collective identities, health Literacy. Well-being and human capital. J. Sport Manag., 27(1): 24-42.

Liu, D. (2016). Social impact of major sports events perceived by host community. Int. J. Sports Mark. Spons., 17(1): 78-91.

Lombardo, G., Mazzocchetti, A., Rapallo, I., Tayser, N., and Cincotti, S. (2019). Assessment of the economic and social impact using SROI: An application to sport companies. Sustainability, 11(13): 3612.

Miles, M. B. and Huberman, A. M. (1994). Qualitative data analysis: An expanded sourcebook. SAGE Publications, Inc.

Mishra, B. (2018). Social Impact Measurement and Investment: Methods, Limitations and Challenges. Transcience, 9(1): 20-47.

Ohmann, S., Jones, I., and Wilkes, K. (2006). The perceived social impacts of the 2006 football World Cup on Munich residents. J. Sport Tour., 11(2): 129-152.

Oshimi, D. (2020). Social impact of mega-sporting events: A test in the Tokyo 2020 Olympic and Paralympic Games, Japanese Sport Management Journal, in press. (in Japanese).

Patton, M. Q. (2002). Two Decades of Developments in Qualitative Inquiry A Personal, Experiential Perspective. Qual. Soc. 
Work. (3): 261-283.

Rossi, P. H., Lipsey, M. W., and Freeman, H. E. (2004). Evaluation: A systematic approach 7th ed.. Thousand Oaks, SAGE.

Rossi, P. H., Lipsey, M. W., and Freeman, H. E. (2005). Evaluation: A systematic approach (Oshima, I., Mori, T., Hiraoka, K., and Motonaga, T., Trans.). Nippon Hyoron Sha Co., Tokyo (Original work published 2004).

Ryan, G. W. and Bernard, H. R. (2003). Techniques to identify themes. Field methods, 15(1): 85-109.

Saito, E. and Nakamura, Y. (2012). Efforts by the sports industry for reconstruction after the great east Japan earthquake disaster and the effects on people in the disaster area. Journal of Japan Society of Sports Industry 22(1): 209-214. (Japanese).

So, I. and Staskevicius, A. (2015). Measuring the "impact" in impact investing. Harvard Business School. https://www.hbs.edu/ socialenterprise/Documents/MeasuringIm pact.pdf (accessed 2020-12-13)

Social Impact Measurement Initiative (2019). Social impact assessment toolset-sports-. Social Impact Management Outcomes and Measurement Working Group Sports Tools Report, 1-55.

Smith, W. W., Pitts, R. E., Wang, W., and Mack, R. W. (2015). What is most important in transferring goodwill from charity run participants to sponsors? Event Manag., 19(3): 305-316.

Snelgrove, R. and Wood, L. (2010). Attracting and leveraging visitors at a charity cycling event. J. Sport Tour., 15(4): 269-285.

Taks, M. (2013). Social sustainability of non-mega sport events in a global world. Eur. J. Sport Soc., 10(2), 121-141.

Vargo, S. L. and Lusch, R. F. (2004). The four service marketing myths: Remnants of a goods based, manufacturing model. J. Serv. Res., 6(4): 324-335.

Won, D., Park, M., and Turner, B. A. (2010). Motivations for participating in health related charity sport events. J. Venue. Event Manag., 1(1): 17-44.

Warner, S. and Dixon, M. A. (2011). Understanding Sense of Community From the Athlete's Perspective, J. Sport Manag., 25(3): 257-271.

Woratschek, H., Horbel, C., and Popp, B. (2014). The sport value framework-a new fundamental logic for analyses in sport management. Eur. Sport Manag. Q., 14(1): 6-24.

Wong-Reiger, D. and David, L. (1995). Using program logic models to plan and evaluate education and prevention programs. In A. J. Love (Ed.), Evaluation methods sourcebook II, 120-135. Evaluation Society.

W. K. Kellogg Foundation. (2004). W. K. Kellogg Foundation logic model development guide. Retrieved 24-June, 2020 from http://www.wkkf.org/knowledge-center/resources/2006/02/WKKellogg-Foundation-Logic-Model-Development-Guide.aspx (accessed 2020-24-06).

Zappalà, G. and Lyons, M. (2009). Recent approaches to measuring social impact in the Third sector: An overview. The centre for social impact. http://www.socialauditnetwork.org.uk/files/ 8913/2938/6375/CSI_Background_Paper_No_5_-_Approaches to_measuring_social_impact_-_150210.pdf (accessed 2020-11$04)$.

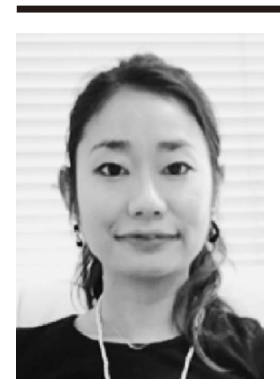

Name:

Ebe Daigo

\section{Affiliation:}

Faculty of Health and Sport Sciences, University of Tsukuba

\section{Address:}

1-1-1 Tennodai, Tsukuba-shi, Ibaraki-ken 305-8575, Japan

Brief Biographical History:

2020- University of Tsukuba

2018-2020 Waseda University

2016-2017 Griffith University

Main Works:

-Daigo, E.: Abilities and structure of dance appreciation based on dance critics interviews. Research in Dance and Physical Education, 4 (1):1-16, 2020.

-Daigo, E. and Filo, K.: Using a Sport Event to Create a Sense of Community: Charity Sport Event Manager Perspectives. Event Management, 24 (1): 57-73, 2020.

Membership in Academic Societies:

- Japan Society of Physical Education, Health and Sport Sciences

-Japanese Society of Management for Physical Education and Sport

-Japanese Association for Sport Management

-Japan NPO Research Association

- Sport Management Association of Australia and New Zealand

-Dance and the Child International 